\title{
Investigation of a new concept of hydrogen supply for a spark-ignition engine
}

The article presents the results of conceptual and research works of an internal combustion engine adapted for hydrogen supply. The engine was equipped with a direct injection of hydrogen into the combustion chamber, allowing the control of the heat release rate. The developed concept of the power supply system and the fuel injection strategy were presented. Initial results of bench tests were also presented.

Key words: hydrogen, combustion engine, direct injection

\section{Introduction}

The rationalization of energy use requires searching for new carriers that in the future may be widely available, and their use will not cause environmental changes. Hydrogen is predicted to be hydrogen in the near future. The most rational use of this fuel in the application to vehicle engines is considered as fuel cells in which the efficiency of energy conversion exceeds 50\%. Currently however, there are serious technological limitations, as well as economic conditions that require solutions before the widespread implementation of this type of power units for transport. However, it is possible to use hydrogen as a fuel for piston combustion engines, which has a valid practical justification. On the one hand, the existing potential of the piston engine industry and the service facilities of this type of drive units will be used, and on the other hand, it will be a period in which users will be prepared to use a new type of energy carrier. For this reason, research centers for hydrogen supply systems for piston combustion engines are being carried out in many research centers, and in some cases advanced operational tests of such types of drive sources are being carried out. In connection with the above, the undertaking of scientific research and development works on the development of hydrogen supply systems is justified in every case.

\section{Hydrogen fuel systems for internal combustion engines}

In currently used hydrogen fuel systems for internal combustion engines, hydrogen is supplied in a gaseous form by dosing to the inlet channel or directly to the cylinder. The method of creating a hydrogen-air mixture in the inlet channel of the engine is currently the most common method of feeding piston engines. It should be noted that this method of hydrogen supply is also used when application of hydrogen as an additional fuel in spark and compression ignition engines takes place. With this method, an increase in the repeatability of ignition can be achieved for the low load range of spark ignition engines. In the case of supplying hydrogen to the inlet channel, this is accomplished via a mixer or a metering valve that is mechanically or electrically controlled. This way of feeding the motor causes a low density of energy supplied to the cylinder. This is due to the high volume fraction of hydrogen in the mixture, relative to the mixture formed with liquid fuels. The stoichiometric constant for hydrogen is 2.38
$\left[\mathrm{Nm}^{3} / \mathrm{Nm}^{3}\right]$, from which it follows that in the stoichiometric mixture the volume of hydrogen is about $30 \%$ of the volume of the total charge delivered to the cylinder. This results in a significant reduction in the unit power of the hydrogen-powered engine compared to the supply of hydrocarbon fuels. In addition, when the engine is powered with a stoichiometric hydrogen-air mixture there is a high risk of self-ignition of the mixture in the inlet channel. Such a situation may for example, occur in the case of uncontrolled backflow of the flame from the combustion chamber during the co-opening of inlet and outlet valves. The mixture formed in the inlet channel heats up from the valves and from the cylinder walls during the filling process, then is compressed and is subject to a strong swirl. These phenomena lead to increased internal and kinetic energy of the hydrogen-air mixture, which promotes uncontrolled selfignition. Then, the pre-ignition reactions intensity growing with the load, increase the risk of self-ignition or anomalies in the combustion process.

The hydrogen direct delivery systems into the combustion chamber just after the filling process are also known. This method of feeding motors with hydrogen shows an analogy to the direct injection of liquid hydrocarbon fuels. This is accomplished by a mechanically or electrically controlled valve. Hydrogen is supplied to the injectors at a pressure of (5-10) MPa. Such a high fuel pressure before the injector results from the necessity of delivering the right dose of hydrogen in a short time, and also because the hydrogen injection takes place at variable pressure in the engine working space. The direct injection of hydrogen into the cylinder also increases the weight of the load in the working space, which results in a significant increase in the unit power of the engine. In addition, such a method of hydrogen delivering to the cylinder effectively eliminates the problems of hydrogen self-ignition in the intake channels and reduces the problems of the combustion anomalies. The problem, however, is the course of the hydrogen-air mixture combustion process in the working space of the reciprocating internal combustion engine, because in the case of engine feeding with a stoichiometric hydrogen-air mixture, the self-ignition phenomenon may occur before the flame is initiated from the electric discharge. The problem is also the high value of the pressure increase $\mathrm{dP} / \mathrm{d} \alpha$, especially for a hydrogen-air mixture with a stoichiometric composition. 


\section{The concept of a hydrogen combustion system in internal combustion engine}

At Cracow University of Technology a power system was developed, in which the main hydrogen dose is delivered directly to the engine's working space during the combustion process. This new hydrogen and air mixture creation and combustion system may be a reason to avoid problems associated with the self-ignition of the combustion mixture or anomalies. Using the wide range of flammability of the hydrogen-air mixture it will be possible to both qualitative and quantitative control of the engine power. The concept shows that in the initial phase of the process, during the filling process, a lean mixture will be created with a composition that allows it to be ignited from the electric discharge on the spark plug. The composition of the mixture should be selected so that the engine can work in the entire speed range without load, overcoming only internal resistance. The role of this first part of the fuel dose is only the initiation of the combustion process, while the remaining main part of the dose is being delivered along the process. Due to the high combustion rate of the hydrogenair mixture, the supply of hydrogen already during the combustion process must be such that the $\mathrm{dP} / \mathrm{d} \alpha$ value must not exceed about $(0.3-0.7) \mathrm{MPa} /{ }^{\circ} \mathrm{C}$.A. It should be noted that the assumed pressure increase of $0.3 \mathrm{MPa} /{ }^{\circ} \mathrm{C}$.A. is usually the maximum value found in spark ignition engines, while the value $0.7 \mathrm{MPa} /{ }^{\circ} \mathrm{C}$.A. corresponds to the pressure increase for the normal combustion process in self-ignition engines.

The proposed concept of hydrogen injection during the combustion process may allow the use of both qualitative and quantitative power control. The choice of regulation will depend on the pressure rise values obtained for a given engine load value, taking into account the criterion of the highest overall efficiency of the engine.

\section{Research object and test bench}

The object of experimental tests was a single-cylinder, self-ignition engine Kipor $186 \mathrm{~F}$, whose technical data is presented in Table 1.

Table 1 . Technical data of a test engine adapted for hydrogen supply

\begin{tabular}{|l|c|c|}
\hline Model & & Kipor 186F \\
\hline Item & Unit & $\begin{array}{r}\text { Single-cylinder, vertical 4-stroke air- } \\
\text { cooled diesel }\end{array}$ \\
\hline Type of engine & & Forced air cooling by flywheel fan \\
\hline Cooling system & Direct injection system \\
\hline $\begin{array}{l}\text { Combustion } \\
\text { system }\end{array}$ & $\mathrm{mm}^{3}$ & $86 \times 70$ \\
\hline Bore x Stroke & $\mathrm{dm}^{3}$ & 0.406 \\
\hline Displacement & - & 19.3 \\
\hline $\begin{array}{l}\text { Compression } \\
\text { ratio }\end{array}$ & $\mathrm{kW}$ & Continuous 6.6, Maximum 7.4 \\
\hline Power output & $\mathrm{rpm}$ & 3600 \\
\hline Speed & & \\
\hline
\end{tabular}

The engine has been adapted for spark ignition and hydrogen supply, directly to the combustion chamber. For this purpose, an additional hole for screwing in the spark plug was made in the cylinder head and a hole for screwing in the pressure sensor. Design changes of the cylinder head are shown in Fig. 1.

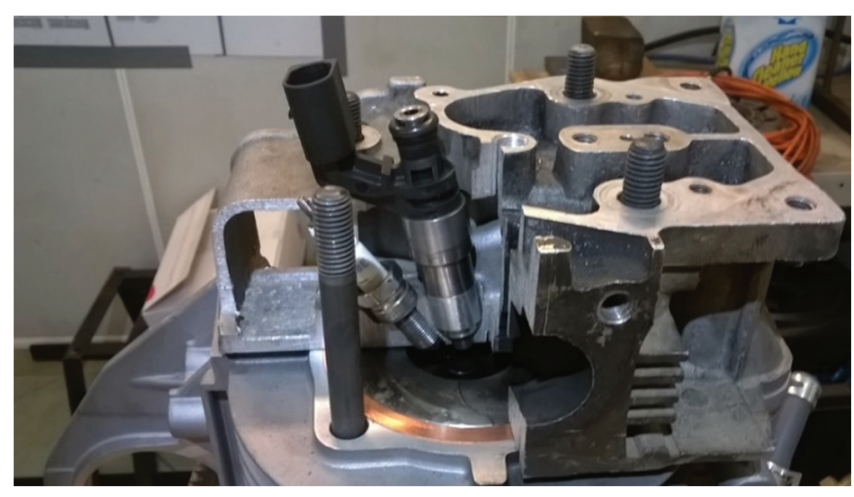

Fig. 1. The scope of structural changes of the engine head adapted for spark ignition and direct hydrogen injection

In the engine being the subject of tests, the combustion chamber, typical for the compression ignition engine, is located in the piston. It has been changed and enlarged, thanks to which the shape similar to so-called Heron chamber has been obtain and the compression ratio decreased from 19.3 to 15.1 . These changes were necessary due to the need to ensure a strong turbulence of the load and due to the protection of the combustion system against anomalies. The design changes of the combustion chamber in the piston are shown in Fig. 2.
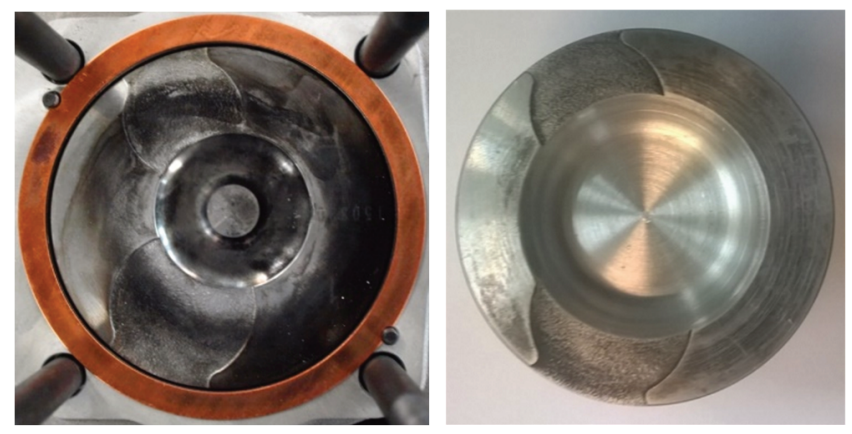

Fig. 2. Piston with a standard (left) and enlarged combustion chamber (right)

The engine has been equipped with throttle, wideband lambda sensor, sensors measuring the intake air and exhaust gas temperatures. Exhaust gas sampling probes for analysis are placed in the exhaust system. The stand has been equipped with a hydrogen consumption measurement system, ignition timing adjustment system and hydrogen injection time control system, as well as a system that allows changing the angle of hydrogen dosage. The computer program written in the LabView environment was responsible for managing changes in the engine's regulation parameters as well as for acquiring measurement data.

The engine was placed on a test bench equipped with an eddy current brake from firm Schenk type W70. Figure 3 presents the tested engine, equipped with control and measurement equipment, placed on the test bench.

The computer control program, developed in the LabView environment, allowed not only for the archiving of measured physical quantities, but also for their current preview. This was very beneficial, especially during the initial measurements, when the range of variation of individual parameters was determined and disturbances were identified. Figure 4 shows the window of the program con- 
trolling the cylinder's indication of the engine being tested. This type of preview allowed for the current identification of combustion anomalies.

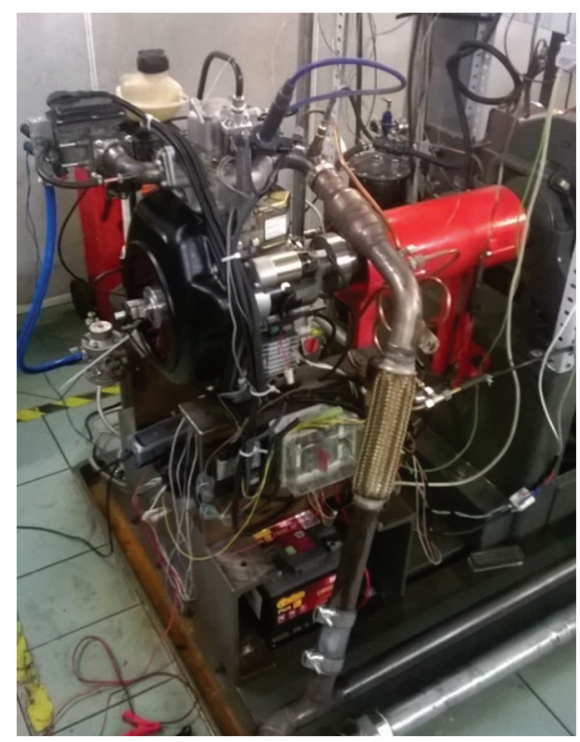

Fig. 3. Investigated engine on the test bench

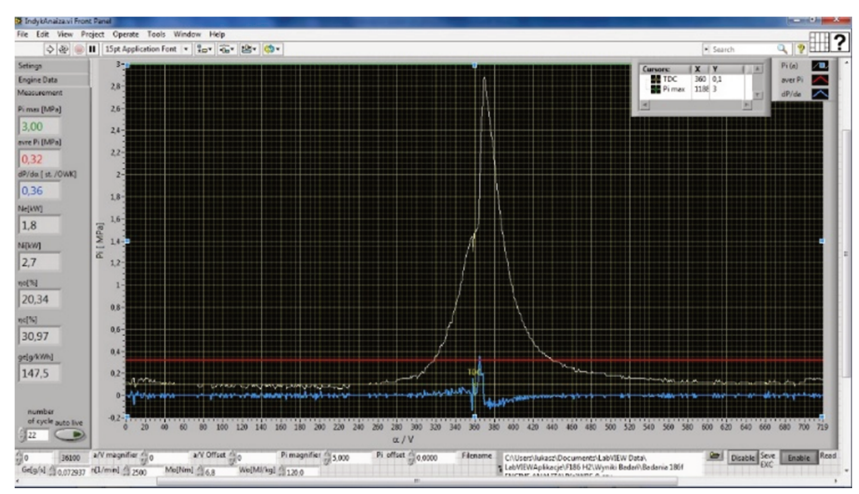

Fig. 4. Window of the current preview of cylinder indication

The remaining measured parameters were presented in the form of a digital record in determined ranges of values, where the exceeding of a given range was signaled by a change in color. Figure 5 shows the window of the preview of measured parameters.

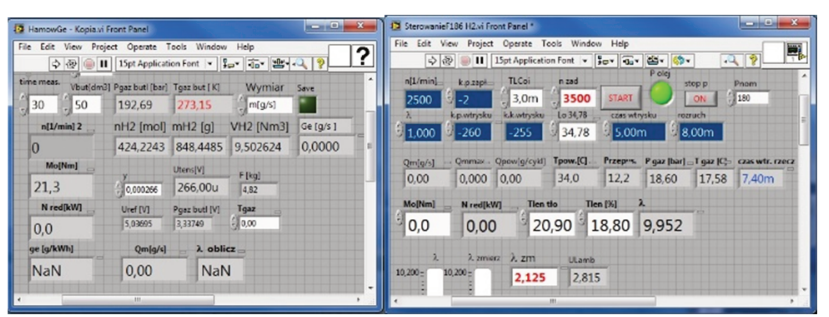

Fig. 5. Windows of the control program controlling the parameters of the eddy current engine break and the tested engine

\section{Research methodology}

Hydrogen-powered engine tests were carried out at a constant rotational speed of $n=2500 \mathrm{rpm}$. For reference purposes, preliminary tests were carried out with indirect hydrogen injection into the intake duct during the filling process. The basic research was carried out while supplying the engine with direct injection into the working space of the cylinder during the process of compression and subsequent combustion. The essence of the research was to create regulatory characteristics of the hydrogen-air mixture composition for different engine load values. The change of the load of the motor was made by changing the degree of throttle opening, while the composition of the mixture was regulated by the change of the injector opening time, with constant hydrogen supply pressure. In the reference tests, when the engine was fed to the inlet channel, the angle of the injection beginning was constant. In the basic tests during direct injection feeding, the value of the injection advance angle was individually selected based on the criterion of the highest value of torque, taking into account the knock combustion limit. A similar criterion was adopted when selecting the ignition advance angle value at each engine work point. The hydrogen injection started during the compression process, while the main part of the hydrogen injection was injected after the spark ignition during the combustion process.

\section{Investigation results}

The results of the initial reference tests of investigated engine equipped with the hydrogen injection system for the intake duct, prepared for three selected throttle opening degrees of $12.5 \%, 25 \%$ and $50 \%$ respectively, are shown in Fig. 6. When working with a small load, the engine could work properly, without knocking effects, while feeding a mixture with a composition of $\lambda=1.4$. There was then a reduced efficiency of the engine, due to the fuel bit and the increased share of mechanical losses in relation to the value of the torque developed. During operation with $50 \%$ load, the correct engine operation was possible while feeding the mixture with the composition of $\lambda=1.85$, at which point the lowest value of unit fuel consumption was obtained.

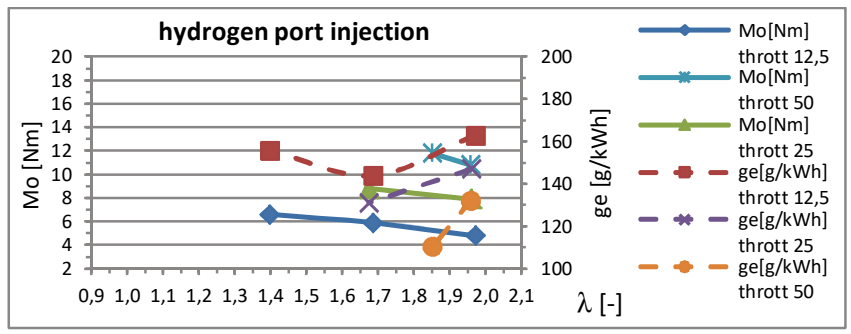

Fig. 6. Regulation characteristics of the mixture composition for selected engine loads (hydrogen injection into the intake pipe)

The use of direct hydrogen injection into the cylinder resulted in a significant extension of the scope of correct engine operation, without occurrence of knock combustion in the richer mixture. For the three selected load states, it was possible to operate the engine properly without knocking effects when feeding with the hydrogen-air mixture close to the stoichiometric composition. This resulted in a significant increase in torque. Direct injection of hydrogen into the cylinder which also lasts after the occurrence of spark discharge, significantly reduces the duration of pre-flame phenomena, when there is a strong charge ionization and thermal dissociation of hydrogen molecules. 
Therefore, the influence of load to any combustion anomalies is less visible and the process of heat release occurs more slowly than during the combustion of homogeneous charge prepared in the filling process.

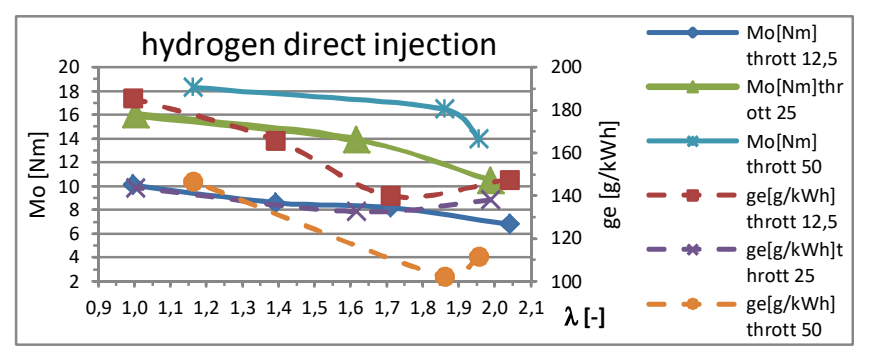

Fig. 7. Regulation characteristics of the mixture composition for selected engine loads (direct injection of hydrogen into the cylinder)

Positive effects of using direct hydrogen injection into the cylinder are confirmed by indicator diagrams. Due to the high rate of hydrogen combustion, both during injection into the intake duct and during direct injection, ignition of the mixture occurred near the TDC position of the piston, which was the most advantageous from the point of view of engine operating parameters. Fig. 8 presents the results of cylinder pressure measurements for different hydrogen supply methods prepared for a throttle opening of $12.5 \%$ and a constant value of the air excess number of $\lambda=1.4$.
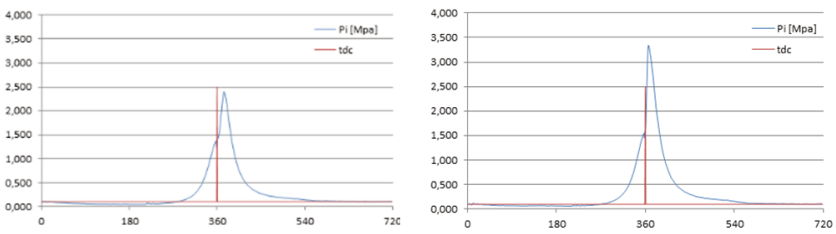

Fig.8. Indicated engine pressure graph with hydrogen injection to the inlet pipe (left) and direct injection (right) (throttle opening $12.5 \%$, air excess number $\lambda=1.4$ )

When the engine was fuelled by direct injection, the maximum combustion pressure of the mixture was clearly higher (about 3.5 $\mathrm{MPa}$ ) as well as the higher rate of pres-

sure increase (up to $0.4 \mathrm{MPa} /{ }^{\circ} \mathrm{C} . \mathrm{A}$.). During hydrogen injection to the inlet channel, where the maximum pressure value was approx. $2.5 \mathrm{MPa}$ and the rate of pressure increase was less than $0.15 \mathrm{MPa} /{ }^{\circ} \mathrm{C}$.A. In both cases, the criterion of absence of knocking effects was retained. A similar relationship was obtained during measurements for throttle opening of $25 \%$ (Fig. 9). In this case, when the engine was supplied with direct hydrogen injection, the maximum cylinder pressure of almost $4 \mathrm{MPa}$ was obtained, and the pressure rise rate was $0.45 \mathrm{MPa} /{ }^{\circ} \mathrm{C}$.A. Hydrogen injection into the intake duct allowed for a maximum pressure of approx. $3 \mathrm{MPa}$, and the rate of pressure increase was approx. $0.16 \mathrm{MPa} /{ }^{\circ} \mathrm{C}$.A.
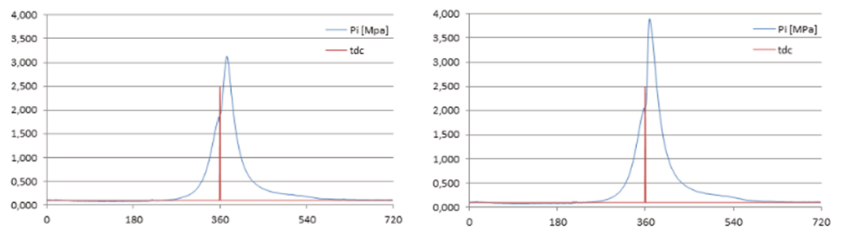

Fig.9. Indicated engine pressure graph with hydrogen injection to the inlet channel (left) and direct injection (right) (throttle opening $25 \%$, air excess number $\lambda=1.6$ )

\section{Conclusions}

The use of direct hydrogen injection, in relation to the injection of hydrogen into the inlet channel, significantly widens the range of correct engine operation, without knocking occurrence. Adoption of an appropriate direct injection strategy allows the combustion of a load with a smaller value of the excess air coefficient, approaching the stoichiometric composition. As a result, a higher value of the maximum cylinder pressure and significantly better operating parameters of the engine are achieved. The significantly higher cylinder pressure increments occurring at the same time do not lead to knocking effects. The applied strategy of direct injection of hydrogen into the piston engine cylinder during the compression process and the combustion process allows the use of hydrogen as a full-value fuel, which can replace standard hydrocarbon fuels.

\section{Bibliography}

[1] BRZEŻAŃSKI, M., CISEK, J., MAREK, W., PAPUGA, T. Investigation of the combustion engine fuelled with hydrogen. V Congress on Combustion Engines. PTNSS-2013-SC192, Bielsko-Biała 2013.

[2] BRZEŻAŃSKI, M., CISEK, J., MAREK, W. et al. Investigation of the combustion engine fueled with hydrogen and mixed n-butanol with iso-butanol. V Congress on Combustion Engines. PTNSS-2013-SC-194, Bielsko-Biała 2013.

Marek Brzezanski, DSc., DEng. - Faculty of Mechanical Engineering, Cracow University of Technology.

e-mail: mbrzez@pk.edu.pl

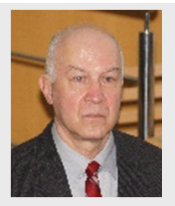

[3] BRZEŻAŃSKI, M., MARECZEK, M., MAREK, W., PAPUGA, T. Determination of operating parameters of industrial engine fuelled with post processing gases with high hydrogen content. IOP Conference Series: Scientific Conference on Automotive Vehicles and Combustion Engines. 2016.

[4] BRZEŻAŃSKI, M., PAPUGA, T., RODAK, Ł. Analysis of creation and combustion process of hydrogen-air mixtures by optical method in isochoric chamber. Combustion Engines. 2017, 170(3).

\footnotetext{
Łukasz Rodak, MEng. - Faculty of Mechanical Engineering, Cracow University of Technology

e-mail: lrodak@pk.edu.pl
} 